\title{
Research on Commercial Multidimensional Innovation Model of Retail Business under Internet Economy Environment
}

\author{
Wei Xing \\ Hunan Vocational College of Modern Logistics, Changsha, China
}

Keywords: Internet; retail industry; business model

\begin{abstract}
The popularity of Internet technology has brought great impact to retail business. On the one hand, online retail has become a trend, and on the other hand, the relationship between retail businesses, customers and suppliers has also undergone substantial changes under the Internet environment. For retail business, how to make timely innovation of business model with the advantage of offline operation has become the key to stimulate the retail businesses vitality in the ever-changing market competition. At present, the domestic research on the business model is still in infant stage. Some researches on the business model innovation of retail business often find it difficult to grasp the advantages of the traditional retailers, and they do not reflect the development trend of "new retail" in future. Based on this, this paper attempts to start from the advantages of traditional retail business, combine the current status and development trend of the current retail industry, and summarizes the commercial multi-dimensional innovation model of retail business under the Internet economic environment.
\end{abstract}

\section{Introduction}

The universal popularity of the Internet has brought about an extraordinary commercial revolution. [1] For consumers, they have obtained a wider range of commodity channels and more adequate product information. For producers, the Internet has shortened the circulation of goods and improved the efficiency of production and circulation.[2] Based on the respective advantages of Internet retailing and traditional retailing, new business models have emerged. Most of the retail formats in China are in the imitation stage without the characteristics of technological innovation. The blind pursuit and excessive imitation of some enterprises have also led to excessive competition and chaotic market order in the retail industry. [3] To a certain extent, there is a slight deviation between the retail industry development and the universal law. All these confused the relationship between the innovation and imitation of the overall development of retail industry in China, and the retail industry needs further transformation and upgrading. This paper attempts to analyze the current business model of the current retail industry, study the elements and laws of the business model innovation theory, explore the feasibility analysis and prospects of the new business model in the new era, then put forward a theoretical and practical approach to the current retail business model.

\section{Introduction to Business Model}

Business model is a system, collection, and ecosystem which consist of many elements. Among all the innovations, the innovation of the business model is the most important for company, because it is the basis of the company's management innovation and technological innovation. The business model is a strategic innovation intention that the market integrates various factors and resources to obtain sustainable development under the objective market conditions and internal conditions. [4] The business model can be summarized as an ecosystem composed of various elements and the relationships between the elements. It refers to an ecological system that the market entity can bring value to the service object, and the market entity and other market participants can achieve a win-win result. [5] It includes a complete set of processes and systems from product, service to management. 


\section{Current Status of Business Model Innovation in China's Retail Industry}

\subsection{Joint venture.}

Joint operation refers to the direct introduction of a commodity brand or certain manufacturer into a store, where the manufacturer independently completes the various links of the purchase, sale and storage of the goods with the help of the store's operating space, and the store only provides the job of auxiliary sales. The corresponding profit model of the joint venture system is the sales income of the retail enterprise and the supplier according to the contract to distribute the products of the joint venture company according to a certain proportion.

\subsection{Lease system.}

Gain revenue by renting market space. In 1987, Wenfeng Mall in Nantong, Jiangsu Province took the lead in the use of counter leasing.

\subsection{Self-operation model.}

There are many methods for self-employment which include the purchase system, develop private brand, and obtain regional exclusive agency rights.

\subsection{Chain-store operation model.}

Chain operation is the scale economy from the single store operations to multi-store chain operations. Chain operation methods include direct sales and franchise.

\subsection{Electronic retail business model.}

E-commerce is the sale of goods or services through the Internet, external networks, electronic data exchange and other online systems. At present, most of the retail enterprises in China featured with low technology, and still use human resources to perform relatively inefficient procurement, sales, logistics, financial processing, which remains a relatively low development stages.

\section{Retail Business Model Innovation in Mobile Internet Environment}

Traditionally, retail industry should conform to the economic laws of the "Internet Plus" era, change the interest-oriented notion of enterprise, establish a consumer experience-centered business thinking, and use $\mathrm{O} 2 \mathrm{O}$ online and offline channels and mobile commerce as innovation platforms to achieve integration of retail sales eco-industrial chain and build a multi-dimensional innovation model of retail business under the background of internet.

\subsection{Retail + consumer experience}

At present, consumers born after 1980s and 1990s have become the main consumers in China's population structure, and they value the unique consumer experience and pursue personalized consumption. The changes in consumption structure and consumption patterns will definitely promote the formation of consumer experience-centered business model. The "Retail + Consumer Experience" model is embodied in: First, the "One-stop family experience shopping center" is a comprehensive experience combined with shopping, dining and entertainment. For example, shopping malls such as Vientiane City and Nanjing Deji Plaza in Shenzhen integrate services such as catering, movies and playgrounds into business models to provide consumers with comprehensive consumer experiences. Second, it is self-service experience supermarket. For instance, Yonghui Supermarket has introduced self-service shopping equipment, which integrates highly intelligent and personalized customization to provide consumers with a deep and complete self-service shopping experience. Third, it is smart business experience model. For example, Intime Department Store and Baidu cooperated to introduce the smart technology BaiduEye. Consumers can obtain product information and GPS shopping mall navigation to gain a full range of smart shopping experience by wearing BaiduEye. 


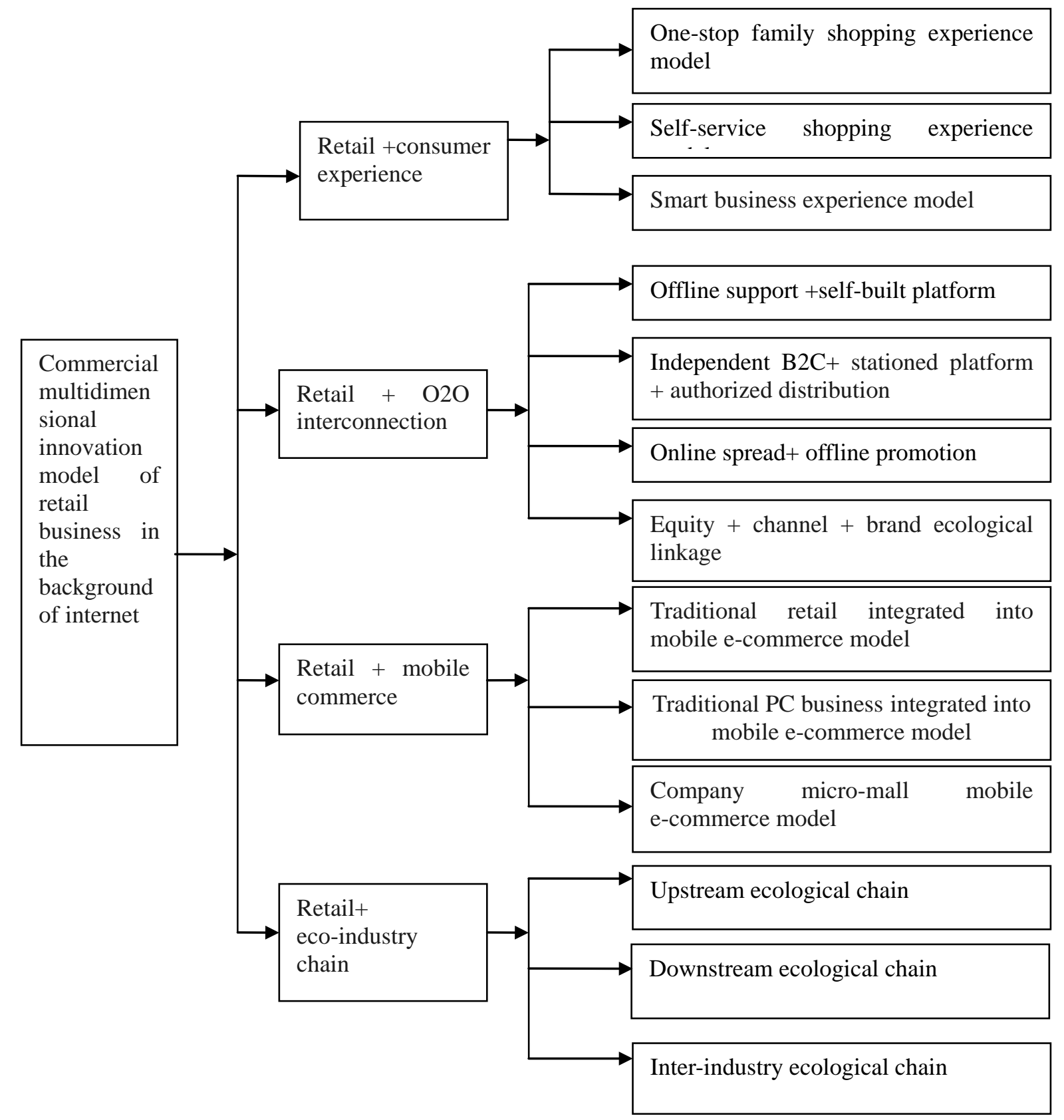

Figure 1 Commercial multidimensional innovation model of retail business in the background of Internet

\subsection{Retail + O2O interconnection}

With the rapid development of Internet technology and information technology, great changes have taken place in the retail channels, which are embodied in "facilitation" and "communization". Online channels provide convenience because of "facilitation," and offline channels have narrowed the distance with consumers because of "communization". The organic link and integration of online and offline channels is the $\mathrm{O} 2 \mathrm{O}$ interconnection model. This model is mainly reflected in several aspects: First, the use of "offline support + self-built platform" model. Companies, such as RT-Mart and Suning Appliance, try hard to enter the online domain and provide integrated services of product sales, brand promotion, finance and logistics through their self-built online malls. Second, take the model of "independent B2C + stationed platform + authorized distribution". For example, clothes brands, such as Yinman and Mecoxlane, not only sell their products through self-built B2C online sales platforms and stationed in third-party e-commerce platforms, but also use franchised distribution methods to actively expand offline entity stores and realize a three-dimensional 
business structure. Third, adopt the "online spread and offline promotion" model, online promote offline upgrade and development, and achieve full integration of online and offline sales. For example, Wanda Group and Baidu reached an in-depth brand strategy cooperation and disseminated brand image and value through Baidu's online media channels, thus realizing the flow from online to offline and creating a new $\mathrm{O} 2 \mathrm{O}$ business model. Fourth, adopt an online and offline comprehensive ecological linkage model of equity + channel + brand. For instance, JD.com shares into Yonghui Supermarket, Ali cooperates with Suning Commerce Group, etc., aims to create new O2Os and provide consumers with comprehensive business services through the integration of the advantageous resources of both parties and use of advanced technologies such as big data, internet of things and financial payment to

\subsection{Retail + mobile commerce}

O2O's online and offline integration is not only the urgent need of entity retailing, but also the needs of e-commerce companies. Today, consumers are pursuing mobile experience and convenience and many retailers have accelerated their transition to mobile commerce. Domestic retail companies are actively responding to this change, and they are widely deploying technologies such as mobile terminals and APPs in the restructuring of business models, stimulating the vigorous development of retail mobile business models to meet consumers' purchases in anytime, anywhere, and anyway. This mainly includes the following aspects: First, the traditional retail industry has integrated into mobile e-commerce models. For example, Intime Department Store launches APP mobile applications, moves traditional department store functions into mobile commerce platforms, and expands online sales and brand promotion. Second, traditional PC business integrated into mobile e-commerce model, such as Jingdong Mall uses APP and Internet of things to comprehensively expand mobile Internet traffic resources, platforms, businesses and supply chain; Third, the company micro-mall mobile e-commerce model, such as Tencent Micro Mall seamlessly connects WeChat public accounts through the WeChat platform entrance to formulate a comprehensive WeChat e-commerce solution.

\subsection{Retail + eco-industry chain}

The Internet sharing economy requires large-scale modern circulation to drive modern production. This requires the retail industry to vigorously promote the degree of modernization, establish a more harmonious relationship between production and sales, form a close and smooth supply chain and industrial chain, and promote the efficiency of retail operations. This is the ecological industry chain model. In the era of "Internet +" integration and development, the ecological main body in the retail industry chain is no longer a single closed enterprise, instead, it connects closely with the market through the Internet and communicates flexibly with suppliers and consumers at all times to jointly create value. This mainly reflected in: First, focus on the commercial value of upstream businesses in the eco-industry chain. For example, Alibaba pioneered and pushed forward the personalized customized services for upstream suppliers, and provided commodity support quickly and efficiently. Second, focus on the commercial value of downstream customers in the eco-industry chain. For example, Taobao focused its search traffic and other resources on small and medium-sized individual businesses and provided a distribution system service and consulting services. Third, it is ecological integration of different formats. For example, "7-11+ Starbucks + Yoshinoya" full-time convenience store integrates consumption, finance, service, and convenience and brings consumers different service ecological experience.

\section{Conclusion}

The "Internet Plus" era is not only an interconnected era, but also an era of continuous integration, sharing, and innovation. Only when the retail business adapts to the development trend of the "Internet +" era and chooses its own business model, can it be the way to innovate the retail business model. Based on the background of "Internet+", this paper constructs the multi-dimensional innovation model of retail business under the background of Internet, and tries to 
give a more comprehensive analysis and feature description of the retail business model. However, the conclusion may still be imperfect and has some limitations, and further detailed researches are encouraged.

\section{References}

[1] Research on Accounts Receivable Financing Model Based on E-Commerce Platform [J]. Jia Yue Sun, Bing Xue, Guang Chao Sun, Dian Peng Cui, Hai Yan Du. Advanced Materials Research. 2013 (683)

[2] The Impact of the Online Channel on Retailers' Performances: An Empirical Evaluation [J]. Yusen Xia,G. Peter Zhang. Decision Sciences. 2010 (3)

[3] Internet Channel Entry: A Strategic Analysis of Mixed Channel Structures [J]. Weon Sang Yoo, Eunkyu Lee. Marketing Science. 2011 (1)

[4] A guide to developing and managing a well-integrated multi-channel retail strategy [J]. Barry Berman, Shawn Thelen. International Journal of Retail \& Distribution Management. 2004 (3)

[5] Porter. The Internet and the Value Chain. Michacel E. Harvard Business. 2001 